\title{
Efficacy of a prepared tissue culture-adapted vaccine against Chlamydia psittaci experimentally in mice
}

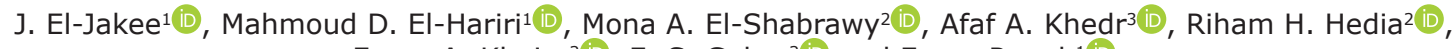 \\ Eman A. Khairy² ${ }^{2}$, E. S. Gaber ${ }^{2}$ and Eman Ragab ${ }^{10}$
}

\begin{abstract}
1. Department of Microbiology, Faculty of Veterinary Medicine, Cairo University, Egypt; 2. Department of Microbiology and Immunology, National Research Center, El Dokki, Cairo, Egypt; 3. Central Laboratory for Evaluation of Veterinary Biologics (CLEVB), Abbasia, Cairo, Egypt.

Corresponding author: Eman Ragab, e-mail: eman_ragab2008@cu.edu.eg

Co-authors: JE: eljakee@cu.edu.eg, MDE: mahmoud_elhariri@yahoo.com, MAE: dr.monaelshabrawy@gmail.com, AAK:afoffa@hotmail.com,RHH: dr.hediamicro@gmail.com,EAK: emankhairy_77@yahoo.com,

ESG: eslambiotechnology21@yahoo.com
\end{abstract}

Received: 19-08-2020, Accepted: 20-10-2020, Published online: 28-11-2020

doi: www.doi.org/10.14202/vetworld.2020.2546-2554 How to cite this article: El-Jakee J, El-Hariri MD, El-Shabrawy MA, Khedr AA, Hedia RH, Khairy EA, Gaber ES, Ragab E (2020) Efficacy of a prepared tissue cultureadapted vaccine against Chlamydia psittaci experimentally in mice, Veterinary World, 13(11): 2546-2554.

\begin{abstract}
Background and Aim: Chlamydia psittaci is an intracellular pathogen with a broad range of hosts and endemic in nearly all bird species as well as many mammalian species. Outbreaks contribute to economic losses, especially due to infection of pet birds, poultry, and livestock. Worse, the organism has a zoonotic effect, and transmission to humans results in severe illness. Therefore, proper control measures need to be applied. We conducted a trial for the preparation and evaluation of inactivated vaccine against $C$. psittaci.
\end{abstract}

Materials and Methods: Three C. psittaci strains (accession nos.: KP942827, KP942828, and KP942829) were grown in embryonated chicken eggs and then propagated for purification in Vero cells. The immunization experiment was experimentally performed in mice, which then were challenged with a virulent $C$. psittaci strain.

Results: The immunization trial revealed nearly 100\% protection after the challenge. The histopathological and immunofluorescence examinations of internal organs revealed that the prepared killed vaccines can effectively reduce chlamydial infection and shedding in animals with the proper level of protection.

Conclusion: Our vaccine can be used to control economic and financial losses resulting from avian chlamydiosis, especially those in poultry industries. The zoonotic transmission risk highlights the need for proper control measures.

Keywords: Chlamydia psittaci, human, immunofluorescence, inactivated vaccine, poultry, Vero cell.

\section{Introduction}

Chlamydia psittaci is an intracellular bacterium that causes avian chlamydiosis disease. It is found in a wide range of birds, including companion, domestic, and wild birds. Cattle egret and hoopoe may be a reservoir for Chlamydiaceae species and thus shed the organisms in their excreta [1]. The prevalence of C. psittaci in lovebirds was investigated where the ompA gene of $C$. psittaci had been detected in fresh fecal droppings and conjunctival swabs [2]. Due to zoonotic transmission, the organism poses a significant public health risk. It was mentioned that at-risk people include bird breeders, pregnant women, workers at quarantine stations, poultry farmers, abattoir workers, veterinarians, pet shop workers, and employees and visitors of zoos, wildlife parks, petting zoos, and circuses [3]. A recent study stated that $C$. psittaci is

Copyright: El-Jakee, et al. Open Access. This article is distributed under the terms of the Creative Commons Attribution 4.0 International License (http://creativecommons.org/licenses/ by/4.0/), which permits unrestricted use, distribution, and reproduction in any medium, provided you give appropriate credit to the original author(s) and the source, provide a link to the Creative Commons license, and indicate if changes were made. The Creative Commons Public Domain Dedication waiver (http:// creativecommons.org/publicdomain/zero/1.0/) applies to the data made available in this article, unless otherwise stated. reported to be the main etiologic agent in $1 \%$ of community-acquired pneumonia globally [4]. Chlamydia does not show strict host specificity. They infect more than 150 avian species, many mammalian species, and an increasing number of isolates from invertebrates. The avian strains were classified into six serovars (A-F) by means of serovar-specific monoclonal antibodies (mAbs) [5,6], while the mammalian strains were divided into nine immunotypes by means of an indirect immunofluorescence test [7].

In Egypt, there have been limited studies about the prevalence of $C$. psittaci in domestic birds, such as pigeons, turkeys, ducks, and chickens [8,9]. This enormous range of host species was matched by the diversity of recognized clinical conditions associated with chlamydial infections. Despite the ability of C. psittaci to induce a variety of disease syndromes, one clinical condition usually predominates in an outbreak or series of related clinical cases. The presenting condition and its severity depend on the strain and virulence of the agent, age, sex, physiological state, and host species, route of infection, degree of exposure to Chlamydia species, environment, and management factors [10]. C. psittaci is nearly endemic in the commercial poultry industry. Devastating outbreaks 
with high mortality occasionally occur, but respiratory signs without mortality characterize most outbreaks. Nevertheless, C. psittaci infections cause significant economic losses, and they are a threat to public health, particularly when this zoonotic agent infects e.g. poultry workers [11].

Reduction of avian Chlamydiosis will affect not only the disease and associated mortality but also it will also reduce the incidence of the carrier state as well as improve breeding performance in birds and mammals. The design of a vaccine and its successful implementation also have the potential to improve human health by decreasing the zoonotic risk and the risk of emergence of antibiotic-resistant strains [12,13].

Vaccination is the best approach for controlling the spread of chlamydial infections in animal and human populations. The main goal for vaccine research is to develop effective vaccines that induce sterile, lifelong, and heterotypic defensive immune responses. To date, the greatest success has been in developing whole organism-based killed or live-attenuated vaccines against the animal pathogens Chlamydia abortus and Chlamydia felis [14,15]. There have been approximately 23 vaccination trials $(10.5 \%)$ against $C$. psittaci within a variety of different hosts, including mice, sheep, birds, Guinea pigs, and cats [16]. Inactivated or killed vaccines are more effective in reducing chlamydial shedding from birds with a good level of protective antibody titer, which creates an effective barrier for protection. Moreover, inactivated vaccines overcome the disadvantages of other types of $C$. psittaci vaccines because it is considered cheap and applicable [12]. DNA vaccination involves integrating the virus' DNA into the DNA of the host cell chromosome to stimulate the generation of antibodies to the DNA, with the aim to induce an immune response that might cross-react with the host DNA [17].

The development of effective vaccines against chlamydial infections requires a clear understanding of the bacterial components that are essential to protective immunity; a suitable vaccine must be developed with these immunogenic elements along with effective delivery systems [18]. Hence, there is an urgent need for an efficient vaccination strategy against C. psittaci. In the present study, for the first time in Egypt, we tried to prepare an inactivated tissue culture vaccine against $C$. psittaci. Vero cells were used to propagate and purify the embryonated chicken egg (ECE) material for the growth of $C$. psittaci strains, which have been used as a bacterin to vaccinate mice as a model.

\section{Materials and Methods}

\section{Ethical approval}

Euthanasia steps and animals' handling followed the Ethical Guidelines of the Cairo University Institutional Animal Care and Use Committee, under the number of CU/11/S/28/17.

\section{Study period and location}

The research work and the immunization trial were carried out from April 2017 to May 2018 at Microbiology Department, Faculty of Veterinary medicine, Cairo University- Egypt.

\section{Microorganisms and seeds preparation}

Three standard Egyptian birds' strains of $C$ psittaci were used for vaccine preparation (accession nos.; KP942827, KP942828, and KP942829, which were kindly obtained from Dr. Eman Ragab, Faculty of Veterinary Medicine, Cairo University). Due to biological hazards regulations, there was difficulty in shipping any standard strains of C. psittaci, as it is categorized as a biological weapon. The strains used were ECE grown $C$. psittaci strains, which were inoculated into specific pathogen-free (SPF) eggs through the yolk sac route of the ECEs [19]. Chicken egg harvesting was performed according to OIE [20]. Titration of infectivity and $\mathrm{EID}_{50}$ for $C$. psittaci strain in SPF eggs were performed [21] and calculated according to Reed and Muench [22].

\section{Preparation of inactivated $C$. psittaci vaccine into Vero cell [23]}

Vero cells were grown in a tissue culture flask containing the growth medium Eagle's Minimal Essential Medium (MEM) with 10\% heat-inactivated fetal bovine serum (FBS) (Hycolon Laboratories, Inc., USA). The flasks were incubated at $37^{\circ} \mathrm{C}$ and examined daily by naked eye with a tissue culture inverted microscope at $200 \times$ and $500 \times$. The growth medium was replaced with a fresh medium when the $\mathrm{pH}$ dropped. When the confluent monolayer was developed, the Vero cells were dispersed with $0.25 \%$ trypsin in a calcium-magnesium-free phosphate buffer saline (PBS) 3 times at $37^{\circ} \mathrm{C}$ until the cells were disaggregated. Then, $1 \mathrm{~mL}$ FBS was added to each flask to stop the action of the trypsin. The Vero cells were then distributed into a 24-well tissue culture plate, where $5 \mathrm{~mL}$ of growth medium required for growth of Vero cells was added with $10 \%$ FBS to each well to stimulate growth of the Vero cells. Next, the plates were incubated at $37^{\circ} \mathrm{C}$ until a confluent sheet in each well was formed. The tissue culture plates were examined daily under the inverted microscope, and the media were replaced with a fresh one when the $\mathrm{pH}$ became acidic. The cell culture was used mainly for two purposes. The first purpose was to purify and propagate the chlamydial cells. The second purpose was to inoculate the infected cells into mice, as they must be propagated into mammalian cells such as mice cells to avoid any reactions with the ECE material.

The ECE obtained $C$. psittaci were diluted in PBS at pH 7.0 and inoculated in the Vero cells at the concentration of $10^{-4} \mathrm{EID}_{50}$ per egg. The inoculated Vero cells were incubated for 5-10 days in $37^{\circ} \mathrm{C}$, and then, the inoculated cells were examined using a fluorescent microscope to detect chlamydial inclusions (Figure-1a). 
A seed consisting of tissue culture was harvested into sterile pooling containers. The infected mixture was centrifuged at $3000 \mathrm{rpm}$ for $15 \mathrm{~min}$ and separated into two layers; supernatant and sediment were each inactivated with an inactivating agent (formalin $0.003 \%$ ) and incubated at $37^{\circ} \mathrm{C}$ overnight. An immune-stimulating adjuvant, Montanide ${ }^{\mathrm{TM}}$ ISA 70(SEPPIC, France), was added to the inactivated antigen to enhance its immunogenicity.

\section{Quality control evaluation of the prepared vaccines}

Safety, sterility, purity, and stability of the prepared vaccines were all evaluated according to the US Food and Drug Administration Code of Federal Regulations [24].

\section{Animals and immunization schedule [25]}

Ninety 2-week-old, $25 \mathrm{~g}$ Swiss Webster mice (Holding Company for Biological Products and Vaccines, Egypt). mice were classified into six groups of 15 mice. Group A was vaccinated with $0.2 \mathrm{~mL}$ of a mixture of inactivated supernatant; Group B was vaccinated with $0.2 \mathrm{~mL}$ of a mixture of inactivated supernatant and adjuvant; Group $\mathrm{C}$ was vaccinated with 0.2 $\mathrm{mL}$ a mixture of inactivated sediment; Group D was vaccinated with $0.2 \mathrm{~mL}$ of a mixture of inactivated sediment and adjuvant; Group E was the positive control mice (unvaccinated/challenged); and Group F the negative control mice received only PBS (unvaccinated/not challenged). All groups were provided with food and water. The experiment duration was 40 days from the beginning of immunization. The prepared vaccine was administered subcutaneously at the beginning of the experiment and through a booster dose after 12 days.

\section{In vivo efficacy and challenge of the prepared vaccines}

A virulent $C$. psittaci strain used for challenge was kindly obtained from Dr. Eman Ragab, Faculty of Veterinary Medicine, CU and harvested in the Vero cell line. The challenge was performed using $0.2 \mathrm{~mL}$ of a solution containing $1 \times 10^{3} \mathrm{EID}_{50}$, of $C$. psittaci and inoculated intraperitoneally 7 days after the booster dose of the vaccine. The degree of protection was assessed according to the severity of the clinical signs and the postmortem lesions and by evaluation of the immune response [25].

\section{Evaluation of the immunization experiment among the vaccinated groups \\ Clinical signs}

The mice in all groups were observed for the development of clinical signs and then were evaluated starting 3 days post-challenge.

\section{Evaluation of $\boldsymbol{C}$. psittaci shedding}

Nasal swabs collected from vaccinated and unvaccinated mice were put in Chlamydia PBS pH 7.2-7.7 medium and inoculated in ECE. Yolk sac impression smears were examined for the presence of viable Chlamydia by staining with Gimenez stain [26].

\section{Histopathological examination}

Autopsy samples were taken from the liver and spleen of the vaccinated and unvaccinated mice in different groups and were fixed in $10 \%$ formol saline for $24 \mathrm{~h}$. The obtained tissue was deparaffinized and stained by hematoxylin and eosin stains for histopathological examination [27].

Direct detection of chlamydial inclusion bodies using the direct immunofluorescence technique [28]

Direct immunofluorescence enables the detection of Chlamydia in impression smears from the mice's internal organs using $2 \mathrm{mAbs}$, one of which is directed against the species trachomatis and the other against the chlamydial antigen. The test was performed with Chlamydia Direct IF kit (BioMérieux, France), following the manufacturer's instructions and examined under a fluorescence microscope (Olympus Microscopes, USA).

Estimation of the serum total protein and albumin [29]

Using a commercial kit (Diamond Diagnostics, Egypt), the total protein and albumin counts were measured in serum samples of the vaccinated and unvaccinated mice. The serum globulin level was determined by subtracting albumin from total serum protein. Measurement of globulin depended on the serum immunoglobulin concentration, which was determined depending on the concentration of total globulins and the A/G [albumin - globulin] ratio.

\section{Statistical analysis}

Statistical analysis was conducted with an R program. One-way analysis of variance was conducted to compare the effectiveness of the used vaccine between different groups. $p \leq 0.05$ was considered to be statistically significant.

\section{Results}

\section{Quality control of the prepared vaccines}

The prepared vaccines were stable with no evidence of any bacterial (aerobic or anaerobic) contaminants or fungal growth after prolonged incubation (14 days) using different inoculated media. No deaths nor local or general reactions were observed in the vaccinated mice.

Evaluation of the immunization experiment among the vaccinated mice

Clinical signs

Clinical signs were observed in both the vaccinated and control groups at 3-9 days post-challenge, as shown in Table-1. It was clear that mild signs were observed among vaccinated groups (Groups A, B, C, and D) compared to the positive control group (Group E), Figure-2. Inclusion bodies of $C$. psittaci were detected in the internal organs of the positive control group (Group E), as shown in Figures- $1 \mathrm{~b}$ and $\mathrm{c}$, while in the vaccinated Groups A, $\mathrm{B}, \mathrm{C}$, and $\mathrm{D}$ at 40 days post-vaccination, no inclusions could be detected.

\section{Evaluation of $\boldsymbol{C}$. psittaci shedding}

C. psittaci excretion was evaluated by inoculation with nasal swabs in ECEs followed by staining of the yolk sac membrane smears with Gimenez stain. 
Table-1: Clinical signs observed among different mice groups.

\begin{tabular}{|c|c|c|}
\hline Group & Clinical signs & $\begin{array}{l}\text { Number of mice showed clinical } \\
\text { signs after challenge }\end{array}$ \\
\hline Group A & Mild & 3 out of $15(20 \%)^{A, a}$ \\
\hline Group B & Mild & 1 out of $15(6.6 \%)^{A, b}$ \\
\hline Group C & Mild & 6 out of $15(40 \%)^{a}$ \\
\hline Group D & Mild & 2 out of $15(13.33 \%)^{A, b}$ \\
\hline Group E & $\begin{array}{l}\text { Moderate to severe: } \\
\text { - Depression and anorexia. } \\
\text { - Cachexia and loose of appetite. } \\
\text { - Moderate-to-severe loss of body weight. } \\
\text { - Conjunctival and nasal discharges that appear to be mucoid. }\end{array}$ & 13 out of $15(86.6 \%)^{\mathrm{B}}$ \\
\hline Group F & $\begin{array}{l}\text { All individuals were normal, and no apparent clinical signs } \\
\text { were observed }\end{array}$ & - \\
\hline
\end{tabular}

Group A=Vaccinated (supernatant+formalin)/challenged. Group B=Vaccinated (supernatant+formalin+adjuvant)/ challenged. Group $C=$ Vaccinated (sediment+formalin)/challenged. Group $D=($ Vaccinated sediment+formalin+adjuvant)/ challenged. Group E=Unvaccinated/challenged (+ve control). Group F=Unvaccinated/not challenged ( - ve control). Letters indicate $p$ value significance (Capital letters A and $B$ indicate significance between all study groups while small letters a, $b, c$, and $d$ indicate significance between the four vaccinated groups)

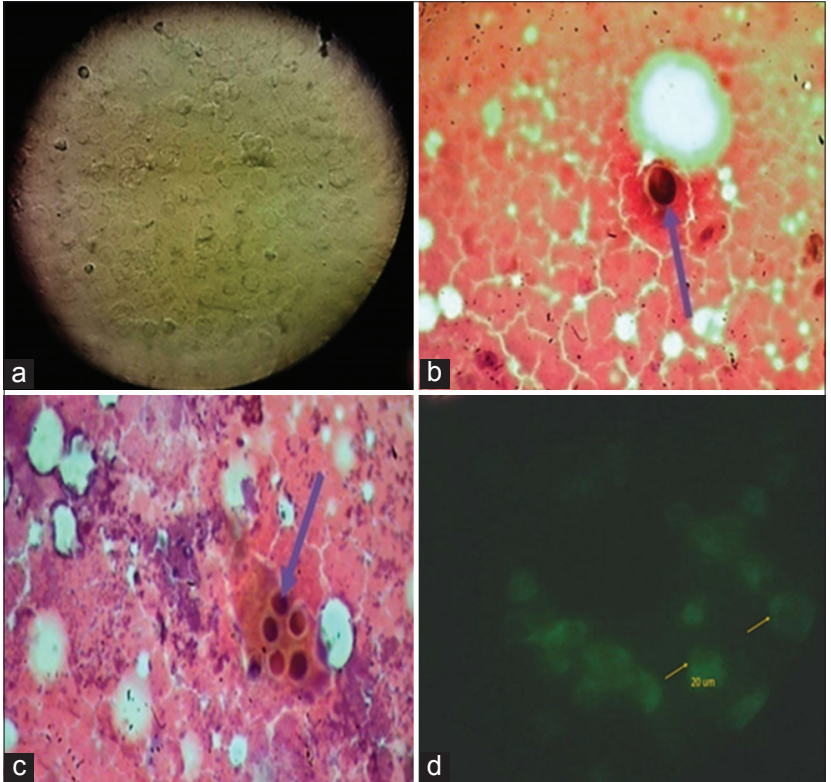

Figure-1: (a) Chlamydia psittaci Egyptian strains in Vero cell showing cytopathic effect that appears in rounding of affected Vero cells and the appearance of pyknotic nuclei. (b and c) Inclusion bodies of C. psittaci were detected in internal organs of the control positive group (Group E) stained with Gimenez stain. (d) Chlamydia direct immunofluorescence for yolk sac smears examined using fluorescein isothiocyanate showing characteristic fluorescent chlamydial bodies over the whole surface of the smear $(400 \times)$.

Chlamydia direct immunofluorescence was performed for yolk sac smears, and there were characteristic fluorescent chlamydial bodies across the entire surface of the smear, as shown in Figure-1d. No shedding was detected in Groups A, B, C, or D, as no chlamydial inclusions were detected. Inclusions were detected for all examined swabs only in Group E, which all were positive.

\section{Histopathological examination}

The histopathological finding from day 40 after mice euthanization is summarized in Table-2, Figures-3 and 4 . The organs that were most affected
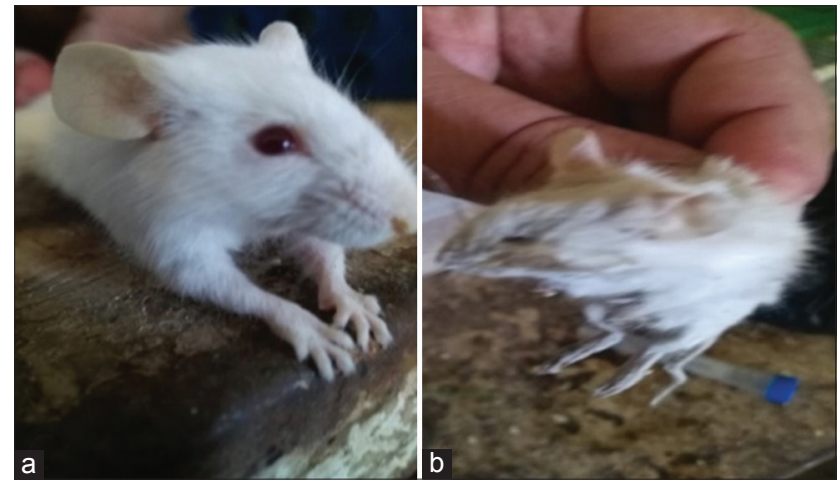

Figure-2: (a) Normal mice in vaccinated group showing mild signs. (b) Control positive (Group E) shows cachexia, depression, loss of weight, and eye inflammation and nasal mucoid discharges.

macroscopically and microscopically as detected using Giemsa stain were the visceral organs (liver and spleen), which were chosen for their histopathology. All the examined tissues obtained from the negative control group showed a normal histological picture. On the other hand, remarkable pathological alterations were observed in the examined organs that were obtained from the positive control group. Otherwise, the vaccinated groups showed an observable normal picture for all of the examined organs.

\section{Estimation of the serum total protein and albumin}

Twelve samples from each group were taken for the estimation of the total protein, albumin, and subsequently globulin to evaluate the status of infection or health conditions. The obtained values are shown in Table-3. In Groups B and C, the globulin values were elevated by from day 19 to day 40 in comparison to that of the control group (Group F) with a decreasing $\mathrm{A} / \mathrm{G}$ ratio. Higher values of albumin and globulin were reached in day 33 post-inoculation.

In Groups $\mathrm{A}$ and $\mathrm{D}$, the albumin and globulin values increased but were less than in Groups B and C in comparison with those of the control group, which decreased in the $\mathrm{A} / \mathrm{G}$ ratio. High values of albumin 
Table-2: Histopathological findings of the vaccinated and non-vaccinated mice's internal organs.

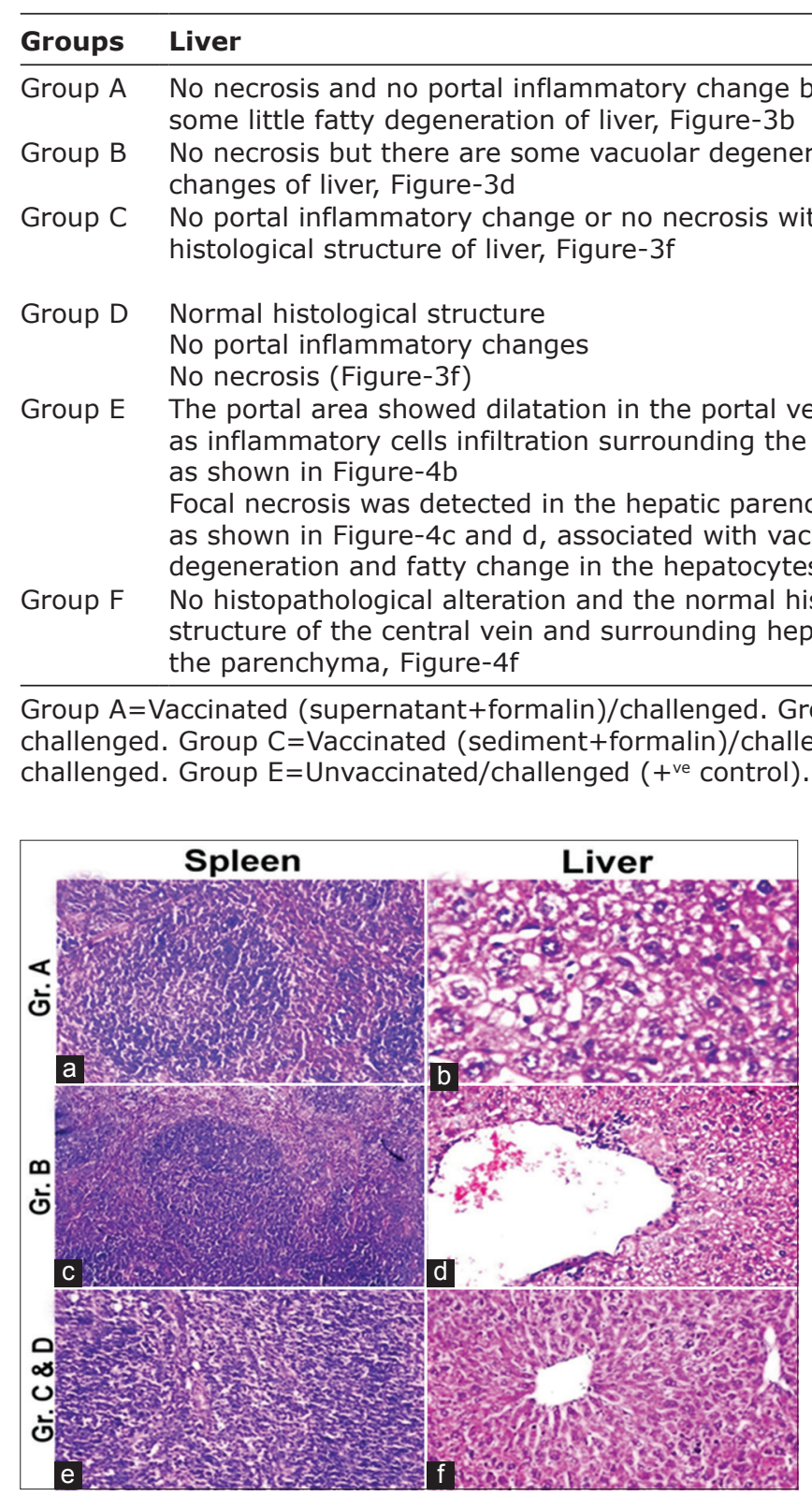

Figure-3: Histopathological findings among vaccinated groups showing normal histological picture of liver and spleen, summarized in Table-2.

and globulin were recorded in day 33 post-inoculation but were low on day 40. In Group E, albumin values decreased with the elevation of globulin values in comparison to those of the control group with an increasing $\mathrm{A} / \mathrm{G}$ ratio.

\section{Post-challenge protection percent verification}

All mice were kept under observation and the clinical signs were recorded. No local reaction was found in all vaccinated mice ( $\mathrm{S} / \mathrm{C}$ injection). There were significant differences between the clinical signs of vaccinated and those of the unvaccinated groups. The number of mice showing clinical signs after challenge was noticed to be higher for the unvaccinated mice (Group F, 86\%) compared to that among vaccinated mice (Groups A, B, C, and D were 20\%, 6.7\%, $40 \%$, and $13.3 \%$, respectively) (Table- 1 ).

\section{Spleen}

Normal histological structure, Figure-3a

Normal histological structure, Figure-3c

Normal histological structure. With no depletion in lymphoid cells in white pulps of spleen, Figure-3e

Normal histological structure. With no depletion in lymphoid cells in white pulps of spleen, Figure-3e

Lymphoid depletion in the white pulps;

Figure-4a

No histopathological alteration and the normal histological structure of lymphoid cells in the white pulps and red pulp; Figure-4e 


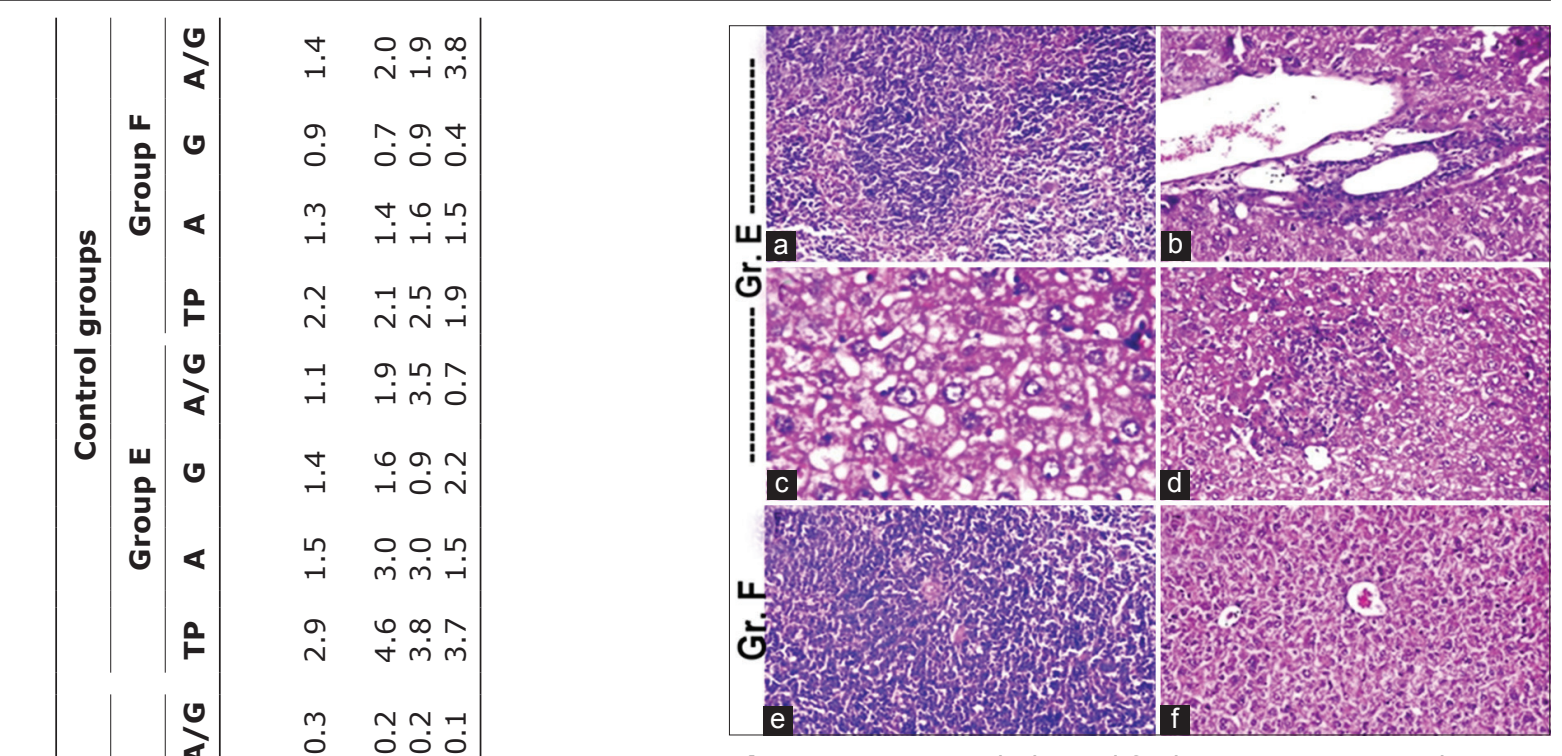

Figure-4: Histopathological findings among control groups showing remarkable pathological alterations were observed in liver and spleen obtained from control positive group, summarized in Table-2.

zoonotic risk, and minimize the emergence of antibiotic-resistant C. psittaci strains [36].

The challenge of developing a vaccine against Chlamydia species that is a cheap killed or inactivated organism that effectively provides long-term protection and is safer to use than the live-attenuated vaccine is to avoid a change of the attenuated strain into a virulent one [14]. Yu et al. [37] conducted mass spectrometry experiments to detect proteins in the chlamydial outer membrane complex from the elementary body of $C$. muridarum. They suggested that conformational intact proteins will be necessary for the efficacy of a recombinant outer membrane protein vaccine. The signal peptide vaccine, which is based on Pgp3-dominant epitopes, plays a significant role with good immunogenicity and protective efficacy against C. psittaci lung infection in BALB/c mice [30].

The present study tested the efficacy of the inactivated whole bacterin vaccine against $C$. psittaci prepared in tissue cell lines and experimentally inoculated in mice. Three Egyptian sequenced strains were selected, grown in ECE, inoculated in Vero cell lines, and inactivated with formalin. Montanide (M-ISA-70) was added as the effective adjuvant to slow the release and give long immunity, especially in pregnant mothers to provide maternal immunity. The quality control of our prepared killed vaccine was studied, and it was pure, sterile, and safe according to the US Food and Drug Administration Code of Federal Regulation [24].

The efficacy of the prepared vaccines was experimentally conducted in 90 mice that were classified into six groups of 15 mice. The first four groups (A-D) were vaccinated, while the fifth and sixth groups were left unvaccinated as the positive control and the negative control, respectively. There was a protection pattern in the form of a variation in the degree of clinical signs between vaccinated, challenged, and 
control groups. Medium-to-severe clinical signs were observed in 13 out of 15 mice $(86.6 \%)$ in the positive control Group E. The shedding test also revealed positive Giemsa samples from Group E. Furthermore, the histopathological findings of the vaccinated groups demonstrated no or minimal alterations in contrast to the severe clinical signs that were recorded for the positive control group.

The presence of $C$. psittaci in the tissues of the immunized mice was evaluated using direct immunofluorescence. Chlamydial inclusions were found in all groups with varied percentages, except in Group F (-ve control) and Group B, which were vaccinated with supernatant+formalin+adjuvant. Indirect fluorescein-conjugated anti-mouse antiserum in combination with the $\mathrm{mAb}$ staining procedures that utilize mAbs directed against chlamydial surface antigens was more sensitive and produced more striking results in comparison to that of histochemical staining [38,39].

An estimate of the globulin was used to evaluate the status of immunity against infection or the degree of health condition by estimating total protein and albumin. It is clear that the globulin values were elevated from day 19 to day 40 (the maximum value was day 33) in vaccinated mice Groups B and C, and to a lesser extent in Groups A and D in comparison to the negative control group (Group F) as the $\mathrm{A} / \mathrm{G}$ ratio decreased. In the positive control group (Group E), the elevated globulin values with low plasma albumin values suggested liver injury [40].

The complete evaluation of the vaccinated groups in comparison to both the negative and positive control groups indicated that the best protection was achieved with the administration of formalized supernatant with adjuvant (Group B) or formalized sediment with adjuvant (Group D), while the less effective groups were those that had been administered the non-adjuvant vaccines (Groups $\mathrm{A}$ and $\mathrm{C}$ ). These results demonstrate the importance of adding adjuvant to the prepared vaccine to improve its efficacy and immune response.

Waldhalm et al. [41] compared the efficacy of C. psittaci bacterin prepared in the mouse L-cell line with a similarly prepared bacterin grown in chicken embryo (CE). It was declared that both bacterins significantly reduced the incidence of abortion and weakness in lambs compared to that of the non-vaccinated control ewes. Notably, the L-cell bacterin elicited a greater antibody response than did the CE bacterin. Rank et al. [42] immunized female guinea pigs with UV light-inactivated $C$. psittaci by different routes: Intravenous, subcutaneous, oral, and ocular routes. Then, all the animals were challenged vaginally with viable chlamydia. The genital infection was intensely reduced for all groups of animals except for the unimmunized controls and those animals immunized orally. A commercial yolk sac-derived adjuvant formaldehyde-inactivated C. abortus strain was found to be effective against ovine enzootic abortion in sheep for as long as 20 years until the disease appeared again in the vaccinated ovine flocks [14].

The main drawback of using a killed or inactivated vaccine in case of immunization against C. psittaci is that the immunity to the intracellular pathogen has been thought to be dependent on the cellular arm of the immune system. However, tissue examination studies often revealed that the intracellular microorganisms could be found in the extracellular space, where they are vulnerable to antibody action. Furthermore, Fc receptor cross-linking can have profound effects on the intracellular milieu through signal transduction $[43,44]$.

\section{Conclusion}

The significant economic impacts and financial losses resulting from avian chlamydiosis, especially those in poultry industries, along with the zoonotic transmission risk highlight the need for proper disease control measures. The killed vaccines used in this trial successfully overcame the disadvantages of using live-attenuated, recombinant, and DNA vaccine techniques. The immunization trial revealed that an inactivated or killed vaccine effectively reduced chlamydial shedding from poultry with an adequate level of protective antibody titer, which creates an effective barrier for protection. The development of an inactive or killed vaccine that is capable of protecting against chlamydial infection presents a special challenge, but it would be the most effective long-term option for the control of chlamydial diseases.

\section{Authors' Contributions}

JE, MDE, and MAE have designed the plan of work, supervised the experiment, and revised the manuscript writing. ER, ESG, EAK, RHH, and AAK shared in all vaccine preparation and evaluation steps. All authors read and approved the final manuscript.

\section{Acknowledgments}

The authors kindly acknowledge Prof. Dr. Adel Bekeer, Professor of Pathology, Faculty of Veterinary Medicine, Department of Pathology, for his support and help during the study. The authors did not receive any funds for this study.

\section{Competing Interests}

The authors declare that they have no competing interests.

\section{Publisher's Note}

Veterinary World remains neutral with regard to jurisdictional claims in published institutional affiliation.

\section{References}

1. El-Jakee, J.K., Osman, K.M., Ezzeldeen, N.A., Ali, H.A. and Mostafa, E.R. (2014) Chlamydia species in free-living cattle egret (Bubulcus ibis) and hoopoe (Upupa epops) in Egypt. Int. J. Vet. Sci. Med., 2(1): 1-6. 
2. Mostafa, E.R., Elhariri, M., Hadia, A.A. and El-Jakee, J.K. (2015) Emergence of Chlamydia psittaci in lovebirds: A new potential risk factor for chlamydiosis. Int. J. Adv. Res. Biol. Sci., 2(11): 1-9.

3. Harkinezhad, T., Geens, T. and Vanrompay, D. (2009) Chlamydophila psittaci infections in birds: A review with emphasis on zoonotic consequences. Vet. Microbiol., 135(1-2): 68-77.

4. Hogerwerf, L., de Gier, B., Baan, B. and van der Hoek, W. (2017) Chlamydia psittaci (psittacosis) as a cause of community-acquired pneumonia: A systematic review and meta-analysis. Epidemiol. Infect., 145(15): 3096-3105.

5. Kebbi-Beghdadi, C., Pilloux, L., Martin, V. and Greub, G. (2020) Eukaryotic cell permeabilisation to identify new putative chlamydial Type III secretion system effectors secreted within host cell cytoplasm. Microorganisms, 8(3): 361.

6. Radomski, N., Einenkel, R., Müller, A. and Knittler, M.R. (2016) Chlamydia-host cell interaction not only from a bird's eye view: Some lessons from Chlamydia psittaci. FEBS Lett., 590(21): 3920-3940.

7. Perez-Martinez, J.A. and Storz, J. (1985) Antigenic diversity of Chlamydia psittaci of mammalian origin determined by microimmunofluorescence. Infect. Immun., 50(3): 905-910.

8. El-Jakee, J., El-Hariri, M.D., El-Shabrawy, M.A. and Gaber, E.S. (2017) Isolation and identification of Chlamydophila in poultry species in Egypt. Int. J. Tech. Res., 10(5): 520-526.

9. Enany, M.E., Mousa, H.A. and Salem, H.A. (2009) Investigations on the prevalence of chlamydiosis in turkey flocks in Egypt with special emphasis on immunopathological characterization of Chlamydophila psittaci. Glob. Vet., 3(5): 424-428.

10. Fong, I.W. (2017) Emerging Zoonoses. A Worldwide Perspective. Springer, Cham. p101-130.

11. Billington, S. (2005) Clinical and zoonotic aspects of psittacosis. In Practice, 27(5): 256-263.

12. O'Shea, H. (2008) Viral pathogens as therapeutic delivery vehicles. In: Patho-Biotechnology Eds: Roy Sleator and Colin Hill ISBN: 978-1-58706-304-6. p126.

13. Prohl, A., Lohr, M., Ostermann, C., Liebler-Tenorio, E., Berndt, A., Schroedl, W. and Reinhold, P. (2015) Evaluation of antimicrobial treatment in a bovine model of acute Chlamydia psittaci infection: Tetracycline versus tetracycline plus rifampicin. Pathog. Dis., 73(1): 1-12.

14. Longbottom, D. and Livingstone, M. (2006) Vaccination against chlamydial infections of man and animals. Vet. J., 171(2): 263-275.

15. Phillips, S., Quigley, B.L. and Timms, P. (2019) Seventy years of Chlamydia vaccine research-limitations of the past and directions for the future. Front. Microbiol., 10:70.

16. Sahu, R., Verma, R., Dixit, S., Igietseme, J.U., Black, C.M., Duncan, S. and Dennis, V.A. (2018) Future of human Chlamydia vaccine: Potential of self-adjuvanting biodegradable nanoparticles as safe vaccine delivery vehicles. Expert Rev. Vaccines, 17(3): 217-227.

17. Liang, S., Bulir, D., Kaushic, C. and Mahony, J. (2017) Considerations for the rational design of a Chlamydia vaccine. Hum. Vaccin. Immunother., 13(4): 831-835.

18. Pierre, P. and Michel, T. (1993) Methods and Techniques of Virology. Marcel Dekker, Inc., New York, Basel, Hong Kong.

19. Andersen, A.A. (1991) Serotyping of Chlamydia psittaci isolates using serovar-specific monoclonal antibodies with the microimmunofluorescence test. J. Clin. Microbiol., 29(4): 707-711.

20. OIE. (2012) Terrestrial Manual 2012, World Organisation for Animal Health, Chapter 2.3.1 Avian Chlamydiosis.

21. Stagg, A.J. (1998) Vaccines against Chlamydia: Approaches and progress. Mol. Med. Today, 4(4): 166-173.

22. Reed, L.J. and Muench, H. (1938) A simple method of estimating fifty percent endpoints. Am. J. Epidemiol., 27(3): 493-497.
23. de la Fuente, J.G., Gutiérrez-Martın, C.B., Ortega, N., Rodríguez-Ferri, E.F., del Rio, M.L., González, O.R. and Salinas, J. (2004) Efficacy of different commercial and new inactivated vaccines against ovine enzootic abortion. Vet. Microbiol., 100(1-2): 65-76.

24. Code of American Federal Regulation (CFR). (2018) PART 103-Experimental Production, Distribution and Evaluation of Biological Products Prior to Licensing 2018.

25. Caro, M.R., Ortega, N., Buendía, A.J., Gallego, M.C., del Río, L., Cuello, F. and Salinas, J. (2003) Relationship between the immune response and protection conferred by new designed inactivated vaccines against ovine enzootic abortion in a mouse model. Vaccine, 21(23): 3126-3136.

26. Giménez, D.F. (1964) Staining rickettsiae in yolk-sac cultures. Stain Technol., 39(3): 135-140.

27. Bancroft, J.D. and Gamble, M., editors. (2008) Theory and Practice of Histological Techniques. Elsevier Health Sciences, Amsterdam.

28. Lecomte, J. (1993) Immunofluorescence. In. Methods and Techniques in Virology. Ch. 13. by P. Payment and M. Trudel. Marcel Dekker Inc., New York. 125-131.

29. Weaver, D.M., Tyler, J.W., Van Metre, D.C., Hostetler, D.E. and Barrington, G.M. (2000) Passive transfer of colostral immunoglobulins in calves. J. Vet. Intern. Med., 14(6): 569-577.

30. Wang, C., Li, Y., Wang, S., Yan, X., Xiao, J., Chen, Y. and $\mathrm{Wu}, \mathrm{Y}$. (2020) Evaluation of a tandem Chlamydia psittaci Pgp3 multiepitope peptide vaccine against a pulmonary chlamydial challenge in mice. Microb. Pathog., 147: 104256.

31. Hafez, H.M. and Hauck, R. (2015) Zoonoses with public health relevance in poultry. In: Zoonoses-Infections Affecting Humans and Animals. Springer, Dordrecht. p103-123.

32. Aitken, I.D. and Longbottom, D. (2004) Enzootic abortion of ewes (ovine chlamydiosis). In: Manual of Diagnostic Tests and Vaccines for Terrestrial Animals (Mammals, Birds and Bees). Office International des Epizooties, Paris. p635-641.

33. Polkinghorne, A., Weston, K.M. and Branley, J. (2020) Recent history of psittacosis in Australia: Expanding our understanding of the epidemiology of this important globally distributed zoonotic disease. Intern. Med. J., 50(2): 246-249.

34. Meeusen, E.N., Walker, J., Peters, A., Pastoret, P.P. and Jungersen, G. (2007) Current status of veterinary vaccines. Clin. Microbiol. Rev., 20(3): 489-510.

35. Burall, L.S., Rodolakis, A., Rekiki, A., Myers, G.S.A. and Bavoil, P.M. (2009) Genomic analysis of an attenuated Chlamydia abortus live vaccine strain reveals defects in central metabolism and surface proteins. Infect. Immun., 77(9): 4161-4167.

36. Hasson, S.A., Al-Busaidi, J.K.Z. and Sallam, T.A. (2015) The past, current and future trends in DNA vaccine immunizations. Asian Pac. J. Trop. Biomed., 5(5): 344-353.

37. Yu, H., Karunakaran, K.P., Jiang, X., Chan, Q., Rose, C., Foster, L.J. and Brunham, R.C. (2020) Comparison of Chlamydia outer membrane complex to recombinant outer membrane proteins as vaccine. Vaccine, 38(16): 3280-3291.

38. Szeredi, L., Schiller, I., Sydler, T., Guscetti, F., Heinen, E., Corboz, L. and Pospischil, A. (1996) Intestinal Chlamydia in finishing pigs. Vet. Pathol., 33(4): 369-374.

39. Buxton, D., Anderson, I.E., Longbottom, D., Livingstone, M., Wattegedera, S. and Entrican, G. (2002) Ovine chlamydial abortion: Characterization of the inflammatory immune response in placental tissues. J. Comp. Pathol., 127(2-3): 133-141.

40. Limdi, J.K. and Hyde, G.M. (2003) Evaluation of abnormal liver function tests. Postgrad. Med. J., 79(932): 307-312.

41. Waldhalm, D.G., DeLong, W.J. and Hall, R.F. (1982) Efficacy of a bacterin prepared from Chlamydia psittaci grown in cell culture for experimental immunization of ewes. Vet. Microbiol, 7(5): 493-498. 
42. Rank, R.G., Batteiger, B.E. and Soderberg, L.S. (1990) Immunization against chlamydial genital infection in guinea pigs with UV-inactivated and viable chlamydiae administered by different routes. Infect. Immun., 58(8): 2599-2605.

43. Lagae, S. (2015) Chlamydia psittaci: Epidemiology,
Zoonosis and Examination of the Innate Immunity, Doctoral Dissertation. Ghent University, Belgium.

44. Jazayeri, S.D. and Poh, C.L. (2019) Recent advances in delivery of veterinary DNA vaccines against avian pathogens. Vet. Res., 50(1): 78.

$* * * * * * * *$ 